\title{
Place and identity: What can we learn from the dead?
}

\author{
Tom Lee
}

\begin{abstract}
In his book Last Landscapes (2003), Ken Warpole notes that, for a number of reasons, cemetery architecture is the most conservative aspect of the institutions and practices surrounding death and memorialisation in the West. This is starting to change, with designers and architects responding to the groundswell of sentiment demanding that we moderns modernise our ceremonies and associated institutions. In the following essay, I look at the different demands and opportunities in urban and rural cemetery design, and focus on the multifunctional roles that cemeteries have played in the past and might yet play again.

This essay is the meeting place of previous work on paddock architecture in the Australian landscape and a recent project looking at death and the landscape. I am interested in the ways that design might respond to the nexus identified by the German philosopher Peter Sloterdijk as 'reactionary religion and progressive technological medicine' (2013: 421), which can bar the possibility of a dignified death and a dignifying place for the dead among the living. This doesn't mean a return to the ostentation of Victorian mourning rituals or adopting the 'death as party' practices of Ghana or Mexico - which isn't to say we can't learn anything from these. Instead, the task seems to be finding a way to give meaning to the values of specific lives and the contexts in which they are embedded, and to provide better support structures (both material, atmospheric and symbolic) for those who gather around the absence created by the departed.
\end{abstract}

Cemeteries offer a unique opportunity to think about the relationship between humans and places because, in a sense, they are the place where humans become indistinguishable from places, slowly dissipating into the 'quasi-eternity' (Foucault 1967: 20) of ruins, remains, organic matter and dust. If cemeteries are where humans become most place-like, they are also, in an inverse but complementary sense, the most human of places, animated by reminders of life-defining mortality. The dead in this sense are mediators between the humans we take ourselves to be and the places we are not.

Cemeteries thus represent a zone where the tension between matter and information is particularly explicit. This is partially due to the fact that, when we die, we become indistinguishable from matter-worm food, as the expression goes. There is also the sense in which humans become information when they die, entering the realm of numbers, dates and names, of seriality and document. The decision then becomes: what kind of information do we want to transmit about friends, relatives or ourselves when we pass into the 'quasi-eternal' 
condition of nothingness? And how do we wish to transmit this information? What atmospheric conditions ought to mediate the encounter between the living, who go to visit, and the silent dead who continue to speak across time?

I begin my investigation with an introduction and brief discussion of French philosopher and historian Michel Foucault's concept 'heterotopia', which, as Foucault suggests, is particularly applicable to the case of the cemetery. This discussion acts as a kind of frontispiece for the more specific considerations of place that follow. Then I compare and contrast a number of different models for cemeteries, using both phenomenological and historical data to account for the distinctiveness and complexity of these places. Firstly, I consider a number of different examples of urban cemeteries, with specific attention to their atmospheric quality and the role that design does or doesn't play in the evocation of atmosphere. I then look at the growing interest in natural burial and the potential shift that the natural burial movement might provoke in the roles played by cemeteries.

Natural burial can be broadly defined as burial practices that pay heed to conservation imperatives, including the use of biodegradable materials, bush regeneration and the maintenance of biodiversity. Such practices are often antipathetic to anthropocentric monumentalism. In this article I'm concerned with how the imperatives of natural burial might entail different ways of perceiving and conceptualising the human and non-human, and how this impacts on the kinds of communicative agency we afford places. For example, how does the atmosphere of a place stand in symbolically for the deceased when there is not an explicit, legible human monument? What might a place tell us about people who are able to choose to be buried there?

To conclude, I reflect in a more speculative fashion on what's possible with regard to the function of a cemetery. I suggest that there is much scope for living spaces to be designed in ways that account for the inevitability of our obligations to the dead, and argue that the physical and virtual spaces in which the dead are kept near have a culture-forming function that can be overlooked and left un-nourished in modern secular societies. Cemeteries have a long history of multifunctionality, as evidenced by the Victorian tradition of cemeteries functioning as gardens and leisure spaces (Martin 2004) and the ambitions of nineteenth-century cemetery reformers such as John Claudius Loudon (Johnson 2008). With a nod to this tradition, I discuss whether it is desirable or viable for the culture-forming role of cemeteries, mourning and remembrance to incorporate and be incorporated within other modern institutions, such as restaurants, farms, museums and, in particular, places that are deemed to offer the kinds of amenity we associate with the natural environment-recognising all the complications that the word 'natural' might involve. 


\section{Unsettled forms and heterotopias}

In Last Landscapes: Architecture of the Cemetery in the West (2003), Ken Worpole notes that, for a number of reasons, cemetery architecture is the most conservative aspect of the institutions and practices surrounding death and memorialisation in the West. Worpole notes that, while the ceremonies surrounding death, such as funeral services, have begun to meet the changing, secular needs of the bereaved, cemetery architecture and design remains, by and large, comparatively stagnant.

One only has to compare the frequency in which images of cemeteries appear as key settings in films and television dramas, compared with the infrequency in which they appear in landscape or architectural magazines, to know that those ultimately responsible for cemetery design are out of touch with public concerns and interests. (Worpole 2003: 8)

Since the publication of Worpole's book, signs have begun to emerge that this is changing, with designers and architects responding to the groundswell of sentiment demanding that we modernise our ceremonies. For example, the influential online architecture and design magazine designboom ran a competition in 2013, Design for Death Architecture, which featured a host of strikingly innovative designs submitted by prominent design and architectural firms.

This renewed interest suggests that the form of the cemetery is, at least in some fields, no longer settled and no longer inevitable. Indeed, as Worpole's exemplary study repeatedly shows, this formal amorphousness, coupled with a perhaps paradoxical singularity of purpose (for a cemetery is always, among other things, a place to dispose of and remember the dead), is a characteristic of the longer history of the cemetery. One need only point to the change from the churchyard cemetery-where the cemetery along with the church is, in a sense, the focal point of the community - to the suburban cemetery-where the dead are ferried out to the suburbs to live in their own satellite city-to begin to understand the kinds of changes amid stability that define the history of the cemetery.

It is this seeming paradox, among a number of others that Michel Foucault picks out as defining heterotopic space. In his lecture 'Of other spaces', Foucault proposes this concept in order to assist in the rethinking of taken-for-granted oppositions regarding space: oppositions between the public and private space, family and social space, leisure and work space, cultural and useful space (1967: 16). Foucault introduces his analysis of 'outer space' alongside the phenomenological interventions into inner space that have been made by thinkers like Gaston Bachelard, making the comparable claim that, like inner space, outer space is never neutral: 
[W]e do not live in a kind of void, inside which we could place individuals and things. We do not live inside a void that could be coloured with diverse shades of light; we live inside a set of relations that delineate emplacements that cannot be equated or in any way superimposed. (1967; cited in Dehaene and De Cauter, 2008: 16)

In other words, experience is the experience of some place or other. It is never emptiness filled, never neutral or pure. The sets of relations that compose a specific place are not outside the human percipient. Rather, the human is an example of one among many things that is composed of the relations between things in a specific context, while never exactly being reducible to them.

Some places in particular seem set aside from what one might advisedly call 'normal goings on', and these are the places that Foucault attempts to make sense of with his analysis of heterotopias. Heterotopias are exemplary in their distinctive and paradoxical otherness from the places and relations with which they are nonetheless connected. Foucault describes a heterotopia as 'a sort of effectively realized utopia'; a no place that, nonetheless, is (1967: 17).

The first example that Foucault cites to give colour to this notion is the mirror, perhaps not something that immediately comes to mind when one thinks of a place. The provocativeness of this example is an indication of the eccentricity and openness required to accompany Foucault in his analysis:

The mirror functions as a heterotopia in the respect that it renders this place that I occupy at the moment when I look at myself in the looking glass at once absolutely real, connected with all the space that surrounds it, and absolutely unreal, since, in order to be perceived, it has to pass through this virtual point, which is over there. (1967: 17)

The level of unreality preserved in the mirror example is, according to Foucault, a characteristic of other spaces that might seem less explicitly virtual. Foucault's list includes boarding schools, cemeteries, monasteries, libraries, high-class brothels, cinemas, colonies and ships (1967: 18-22).

Thinking through the examples and the criteria Foucault offers, it is tempting to conclude that heterotopic space is less an essential feature of particular places, and more helpful as a tool to think about the complexity of different places in general. Indeed, the versatility of the concept is evident when looking at the way it has been employed by other thinkers. For example, the German philosopher Peter Sloterdijk offers the following candidates as heterotopias: sports venues, holiday islands, places of pilgrimage, slums, car parks, different kinds of no-go areas and space stations (2013: 222). Foucault seems right in his specification that 'heterotopology', as he calls it, is not a science, but a systematic description of some other kind (1967: 17). There is no singular or settled list of heterotopias. What does and doesn't qualify is always up for grabs. 
Foucault lists six guiding criteria that assist in the systematic, though not scientific, identification and description of heterotopias (1967: 17). One: all cultures have heterotopias, though there is no universal heterotopia. Two: the same heterotopia may function differently at different times in the history of a culture. Three: heterotopias hold together several otherwise contrasting or even incompatible functions or performative spaces. Four: heterotopias function according to their capacity to operate outside time, in other words, they are necessarily anachronistic. Five: heterotopias feature distinctive conditions of entry, whereby entrants must adopt certain ritualised attitudes or behaviour. Six: heterotopias pose either an illusory or compensatory function whereby the illusory nature of real space is exposed, or reflected in a more perfect form (1967: 18-22).

Foucault twice uses the cemetery as an example to illustrate what these criteria mean more specifically. In one instance, he calls on the cemetery to make sense of the idea that heterotopias express an anachronistic temporality. Cemeteries are time dense places amid sets of other places where time seems too speedily effervescent to provoke pause. When one enters a cemetery, one cannot help but feel as though one has entered a different time, or a place that bears a different relation to time. This feature of cemetery space is worth noting for the sections that follow. Foucault also uses the cemetery as an example to give descriptive detail to the second criteria listed above, in the sense that it is a place that has always been with human civilisations - 'has not ceased to exist' (1967: 18) - but which has functioned in different ways over time. In other words, the cemetery as heterotopia has both a precise and a mutable function, both stable and changeful. This aspect of the cemetery is also relevant to underline for the analysis that follows.

\section{Examples of cemeteries}

Like all heterotopias, cemeteries have distinctive atmospheres. This, however, doesn't mean that the atmosphere will be thoughtfully designed. In this section, I look at different examples of urban cemeteries and offer some suggestions as to what is possible in urban cemetery design. I set up a suggestive rather than systematic contrast between what does and doesn't seem to work with a focus on Abney Park and Tower Hamlets in London, two mid-nineteenthcentury cemeteries that are now no longer managed as cemeteries but fulfil other public functions. Emphasis on the United Kingdom affords a tracing out of historical and cultural convergences and divergences with Australia. While the channels of influence between UK and Australian examples are more dynamic and divergent than is often supposed (Martin 2004), one can readily read the inheritance of UK cultural conventions in Australian cemetery design and management. For example, in the Australian context we see iterations of the Victorian garden cemetery and a similar shift in values towards cemetery 
spaces that have been increasingly designed for ease of management, hygiene, equality, uniformity and order. More recently, too, natural burial, which is more established in the United Kingdom, is being recognised in Australia. While the uptake is slow, legislative change, community groups and proprietors are making natural burial a viable and desirable option (Brice 2013).

Both Abney Park and Tower Hamlets function as urban woodlands and, in this sense, fulfil a multifunctional role comparable to the churchyard cemetery, which, in addition to being a place for the dead to rest, was also a meeting point for the community, and the Victorian garden cemetery, which was a place for leisure as well as mourning (Martin 2004). The role played by Abney Park and Tower Hamlets as urban woodlands can be read as an evolution of the garden cemetery ideal that informed their initial planting in the mid-nineteenth century. They are explicitly recognised as sanctuaries for wildlife as well as human remains. This observation points to the following section where I discuss natural burial grounds, which also commonly function as woodlands or parks as well as cemeteries.

One of the striking things about Abney Park and Tower Hamlets is that they are almost overrun by understory vegetation. This includes many plants that are cropped or regarded as weeds in an Australian context, such as lucerne, nettle, bulbs of all kinds, daisies, canola and wild roses. This vegetation, along with the well-established evergreen trees, creates a kaleidoscopic atmosphere in continually shifting gradients of green. Scattered among the growth are titled stones, greening with moss and lichen. There is seemingly no way to distinguish the plan of the graves from the plan of the forest, with bush and grave springing alike from the soil.

Abney Park and Tower Hamlets both point to a long history of cemeteries incorporating design aspects that are proper to other genres of place. Tower Hamlets is described by the Friends of Tower Hamlets Cemetery Park as 'the most urban woodland in London' (2014), and Abney Park was initially designed as a garden and arboretum as well as a cemetery. While previously they might have been places to go to remember deceased family and friends, they now draw together a variety of different publics and fulfil a range of functions: workspaces for recreational and amateur gardeners and stone-carving collectives, educational facilities for woodland conservationists, and venues for holiday clubs that allow kids to make cubbies and build rope swings among the headstones. Tower Hamlets supports a network of over 3,000 volunteers and is used by over 8,500 local school children as an outdoor classroom (Friends of Tower Hamlets Cemetery Park 2014).

In contrast with the distinctive atmosphere of Abney Park and Tower Hamlets, the cemeteries in or on the fringes of Australia's urban centres-and in the majority of lawn cemeteries - are notable for the absence of a sense that one 
has entered an interior, a sheltered space that is living and breathing as much as dead. This contrast is apparent in cemeteries like Rookwood and Macquarie Park Cemetery in Sydney, which favour short lawns and sparse, orderly plantings.

Rookwood is the largest cemetery in the southern hemisphere and the largest greenspace in Sydney. Built on land acquired by the government in 1862, it houses a variety of plant and animal life and is known for its arrangement of burial plots for various religious denominations in a suburb-like format. Despite this non-human and human diversity, the cemetery suffers from the same atmospheric deficiencies as many cemeteries that have been designed according to strict, rectilinear geometry and what might be deemed an excessive prioritisation of hygiene (Johnson 2008). As Julie Rugg points out in her article 'Lawn cemeteries: The emergence of a new landscape of death', post-Victorian cemetery design and management 'embraced clean lines, eschewed clutter and saw virtue in uniformity' (2006: 219). These are values that no doubt make sense when viewed as a reaction to the ostentation and uneven expression of status in Victorian cemeteries and mourning conventions. Similarly, one can see the argument for cemeteries designed to accommodate lawn-mowing technologies and other maintenance requirements in the absence of cheap or willing labour. The often-needless hostility shown to disorder and mess can result, however, in sterile, exposed landscapes that are uninviting to humans and animals.

Based on the abundance of closely shorn turf in the built environment, one might be forgiven for thinking that hostility to long grass is a defining feature of the Australian attitude to both public and private space. Some promising counter examples can be found in recent urban architectural initiatives, such as Neeson Murcutt Architects' award-winning designs for Prince Alfred Park in Sydney, which features a meadow of native grasses. A well-kept lawn, however, arguably remains a sign of civic virtue, of cared for and well-managed space. This is regrettable in light of the role that established grasses can play in the evocation of a space that has been set aside, as they do at Tower Hamlets, Abney Park and some of the natural burial grounds discussed in the next section. Grass with height and density contributes significantly to the spatial diversity and distinctiveness of the landscape. It creates a sense of 'in-ness' that is different to the 'in-ness' created by the tree canopy and certainly to the typically smooth, level surfaces common to urban places. Thick grass is troublesome. It supports the creepy crawlies that exist in an antagonistic relationship with the clean, safe, manageable spaces to which certain iterations of modern architecture and design aspire. Messy grass signifies neglect. Something significant goes missing, however, when the band between waist and foot is reduced to a condition in which flatness and exposure is its ideal. 
In Last Landscapes, Worpole offers a similar critique of a certain kind of popular twentieth-century cemetery:

[T]his great, dry grass desert with uniform rows of standardized graves seemed like a grim card-game of Patience left incomplete. There is no shelter from the sun, no trees lean over the graves to shade them, no slopes in the landscape to lift one's eyes to the sky, or deflect from the endless monotony of what is less a place of consolation and more like a killing field, or a sports field hastily dug up for mass burials after some terrible atrocity. (2003: 56)

The specific cemetery in this case is in Kent, England, and Worpole passed it on route to Derek Jarman's idyllic memorial garden, Prospect Cottage. Worpole's comment that flat, lawned spaces do little to 'lift one's eyes' or to break up the monotony of a homogenous spatial field is revealing with regard to an argument that one might make in favour of long grasses in cemeteries. Whereas flat lawns aspire to a singular spatial dimension, tall grasses enfold multiple, woven pleats. In addition to offering a variety of shelters for insects, reptiles and birds, this spatial multi-dimensionality allows the eye to follow textured, visual paths inward to rest on rudimentary interiors: the partially opaque microworlds of other beings, living and non-living.

\section{Natural burial grounds}

In contrast to the prototypical, well-maintained, twentieth-century cemetery in the West, natural burial grounds often support flourishing grasslands. In part this is due to the different set of priorities that define natural burial grounds. Key among these is the shift in emphasis from exclusively human monumentalism to democratic ambitions whereby design and architecture supplement and support non-human dwelling spaces and their occupants. In the words of Robert Larkins, natural burials are 'natural monuments' (2007: 105)-a phrase that might ideally lead to the rethinking of views about the relationship between humans and nature and the obligations of the former to the latter.

Indeed, it seems a mistake to associate places like natural burial grounds, which involve an emphasis on conservation measures, with 'the natural' as opposed to 'the human'. Clearly such landscapes are included within humanspheres and designed in this sense: they are made to house the human body as it moves across the threshold from the living to the dead, from the cultural to the natural. But in part even this framing (cultural/natural) is merely rhetorical, for the human body is always natural and cultural at the same time and this doesn't change whether it is dead or alive. What's more, it is a misapprehension of anthropocentrism to regard any project that doesn't telegraph its humanness as having ambitions to return to nature. To call a landscape a 'natural burial ground' is a shade oxymoronic in this sense. 
Colney Woodland Burial Park, near Norwich, England, is both cemetery and woodland, both woodland and park. The distinctive feature of this natural burial ground, when compared with the cemeteries mentioned above, is the absence of headstones in favour of carved wooden memorials, and a radial rather than linear arrangement of graves. Local woodworkers are usually employed to make personalised monuments for each grave that conform to limitations in size but not in form. Birds and other animals are among the more popular monuments, with others ranging from books to soccer balls. The graves are arranged in rough, concentric rings encircling specially chosen trees. The effect is a greater sense of harmony between the monuments and other aspects of the landscape. The place is free from the often imposing monumentalism that characterises cemeteries dominated by large stone tombs and gravestones, and which lack the sense of enveloping tranquillity created by the forest and its undergrowth. The twin objectives of supporting a native woodland and offering a resting place for the dead successfully creates an atmosphere that, while less explicitly human in a sense, is nonetheless thoughtfully designed in terms of its appeal to human emotions. As Worpole notes of Colney, 'Although the mature woodland seems completely "natural", it has been the subject of judicious landscape planning' (2003: 193). It is a kind of planning that is less to do with human permanence than with the creation and maintenance of a kind of place that, to some degree, makes the persistence of humans more likely, in other words, a 'natural monument'.

In his discussion of Colney, and natural burial grounds more generally, Worpole makes a further point that is pertinent to broader questions to do with landscape and meaning from which the present analysis emerges. Quoting from Kenneth Frampton's work on critical regionalism, he suggests that many newer cemeteries are not designed with the distinctive topographical features of the landscape in mind and that, in order to ensure places retain an identity rather than drifting into the realm of placelessness, design should put greater emphasis on topography (2003: 194). While the landscape at Colney could be read as 'anti-architectural', to use Worpole's term (2003: 194), it is in fact carefully designed and, even if its notional ambitions are to return both bodies and the woodland to nature, this is a nature that has depended on human intervention in order persist-and humans, in turn, might one day come to depend upon it, or places like it.

Similar uncertainties surround questions to do with natural burial grounds and design in the chapter, 'From cabbages to cadavers: Natural burial down on the farm' (Clayden et al. 2010: 119-38), which forms part of an extended study on spaces for the dead and dying (Maddrell and Sidaway 2010). The authors focus on a particular kind of natural burial ground that involves the conversion of previously farmed land, on private property, into a public gravesite. This case study is particularly relevant to the Australian situation in light of Robert Larkins' advice in Funeral Rights, namely that, 'Natural burial grounds appear to be the best option for countries like Australia, which have plenty of land that could 
do with some loving care' (2007: 109). Clayden et al. use qualitative research methods, such as interviews with landholders, to discuss the varied motivations and considerations for setting up a natural burial ground.

Converting a piece of land from a farmed paddock into a burial ground involves significant changes, both in terms of the way the land looks and the way it is regarded by owners. The farming families interviewed by Clayden et al. reveal a variety of different design considerations (even though they didn't think of themselves as designers): how the burial ground will be marked out from the rest of the property, the visual appeal of the site and the views it offers onto the surrounding countryside, what kind of entrance and signage it will have, the general layout of different amenities (car parks, for example) and the long-term plans for the land (i.e. whether it will remain woodland or return to grazing and cultivation) (2010: 127-29). Different landholders adopt different practices, but each involves a vision that is bound up with an awareness of the topographical distinctiveness of the land and past farming practices, such as the spreading of fertilisers, that have sometimes imperceptibly and sometimes dramatically altered the environment. This makes the farmer as designer fulfil a different role to that of a professional landscape design team, whose perceptual history is less dependent on the landscape undergoing alterations - for better or worse. In the examples the authors include, there is an expressed desire on the part of the farmers 'to work with the existing landscape fabric and to integrate the burial ground with the farm' (2010: 130). The dual considerations of making the burial ground distinctive, while integrating it with the rest of the property, is reminiscent of the tensions that Michel Foucault names as defining heterotopic spaces.

Farmers, like gardeners, designers and architects, though perhaps less explicitly so, are always to some extent the creators of habitats. Traditionally, this habitat creation has largely been in the service of yields, whether in the form of plants or animal products. The case of these farmers represents an interesting shift in priorities for habitat creation, not only in the sense that they are less focused on yields but also in the shift from creating places for animal and plants that humans influence indirectly from a distance through consumption, to the creation of places that are used by humans for the dual purpose of burying the dead and creating an environment for animals and plants. If, as the architect Adolf Loos suggests, architecture begins with the places humans create for their dead to rest (1910, cited in Worpole 2003: 6), one can read this shift in farming practices as the explication of latent architectural and design considerations. Importantly, farmers in these instances still work the land through from a 'dwelling' perspective, with a unique knowledge of the 'taskscape' that defines a given place-to adopt two of anthropologist Tim Ingold's terms (cited in Clayden et al. 2010: 120-21). These aptitudes are employed in the service of concerns that are more properly those of architecture and design rather than those of intensive 
agriculture, which is to say, concerns that include the what and how a place speaks to other humans, as well as accommodating the non-humans that share sovereignty of the land.

A final point worth considering in relation to the 'From cabbages to cadavers' study is the connectedness of the burial ground and the rest of the farm and subsequent flow-on effects regarding the way the rest of the farm operates. In one example, a farm operator discusses installing wind turbines on the farm due to a vague but growing commitment to environmental concerns and, importantly in this context, as a way of advertising the burial ground in a manner that is consistent with its conservation imperatives (Clayden et al. 2010: 135). This seems a modest example highlighting the dynamism that exists between the kinds of places humans create and identity. One does not simply undergo a change of vocation and then effect a change on the place one inhabits. Rather, identity is at each stage in some sense composed of the place it wrestles to change, and there is feedback between the two. In other words, the relationship between place and identity is not a zero sum game where inputs and output are equivalent or where the conditions of actors (human and non-human) are stable. The creation of a new place or a new relationship to place is the creation of a new identity, which is formed out of the place it has helped change.

\section{Conclusion: Potentials for multifunctionality}

Based on a very long anthropological history, it is probable that humans will always create places and things to remember their dead. Based on the same history, and with an eye to Michel Foucault's remarks on the shift from the churchyard to the suburban cemetery, those places will also continue to change in both subtle and dramatic ways. Though talk of God's death may be premature, the protracted waning of theistic world views, and with religion offering an increasingly less compelling reservoir for personal and group identification, it seems right that publics have access to new services that are modelled on concerns proper to the contemporary and the future. In this final section, I briefly speculate as to what some of those changes might be. My speculations are informed by the assumption that the only viable, future-directed, purposesparking, group-binding concerns will involve the maintenance of places that offer something aesthetically rewarding and productive of resilient ecosystems.

As 'From cabbages to cadavers' points out, natural burial grounds suggest a diversity of experiences and purposes - particularly when compared to the probable form of a twentieth-century cemetery in the West: 'a natural burial ground is unlike a cemetery with its singular mortuary purpose, separated off from both everyday life and other life course transitions. Instead, like the churchyard, it has connections with a broader range of belief systems and experiences' (Clayden et al. 2010: 135). So, already in these new burial grounds, one witnesses 
the addition of new functions, the formation of new publics. The associations of burial and the protection and support of threatened ecologies (Barrett and Barrett 2001), as well as a general connectedness to place, might in the future become more explicit. It is also conceivable that such burial grounds might offer an educative function in the same sense that churches once did and in the way that museums and galleries currently do. Indeed, the recent efforts by museums in the United Kingdom, Australia and America, in particular, to respond to dissatisfaction with existing school systems through the creation of innovative educational programs, seems to offer more than a subtle hint at the potential roles a burial ground might play. This is particularly the case if one believes in the value of children having a robust understanding of death-any conception of life without such an understanding is clearly significantly lacking. One can readily imagine a natural burial ground or series of natural burial grounds that teach ecological and death awareness alongside more traditional functions.

In Australia, institutions like Landcare have historically played a role in making environmentally concerned publics explicit and bringing together people who identify as conservationists. It seems feasible that a natural burial ground might take on this role in the absence of state funding for conservation groups, with funds raised from the purchase of grave plots being put into the establishment and maintenance of educational programs and events. Robert Larkins notes as much when he suggests that natural burial grounds might offer Landcare and Landcare-like organisations 'a continuing revenue base for their conservation work' (2007: 108). Like museums, which are already well resourced to offer educational services due to their abundant material curiosities, natural burial grounds could make use of existing conservation programs, landscape designs, and memorial designs to give students an example-rich, atmospherespecific education. Such programs might teach from a range of different examples that express the intimacy of human feeling, thinking, memory and place. These examples might be sourced from disciplines including design, poetry, literature, art, indigenous history, anthropology, philosophy and science. Woodworkers, employed to make memorials, might offer workshops alongside farmers telling stories about their land and scientists with a good knowledge of the species diversity in the area. Burial grounds like Colney already hold wellattended functions on mother's and father's days and at Christmas and Easter. These measures aim to create a sense of community on those days that are most difficult for those who have lost loved ones. Here the burial ground is playing an explicitly therapeutic role in a manner that has historically been associated with the church. As the success of Landcare in Australia shows, from a secular perspective, there seem few issues as urgent or as likely to garner community attention as the necessity of ecological awareness in the face of an ecological crisis. In this sense, mourning and remembrance might be conducted as part of a constructive, future-directed effort to create atmospherically distinctive, ecologically diverse and sustainable places for the dead to be kept at a near distance. 
Tom Lee is a writer, researcher and teacher who works largely at the University of Technology Sydney. He has a PhD in comparative literature and two years' teaching experience in design. He has published academic articles, poetry, essays and short fiction on a variety of topics, including the effect of naughtiness, feelings of the feet and the lists of W.G. Sebald. He is a 2014 recipient of the Marten Bequest Travelling Scholarship for the category of prose.

\section{References}

Barrett, G.W. and Barrett, T.L., 2001, 'Cemeteries as repositories of natural and cultural diversity', Conservation Biology, vol. 15, no. 6, pp. 1820-24.

Brice, R., 2013, 'Natural burials now recognised in South Australia', ABC Online, 6 June, viewed 21 March 2015, www.abc.net.au/news/2013-06-05/naturalburials-legislation-passes-in-south-australia/4734940.

Clayden, A., Green, T., Hockey, J. and Powell, M., 2010, 'From cabbages to cadavers: Natural burial down on the farm', in A. Maddrell and J. Sidaway (eds), Deathscapes: Spaces for Death, Dying, Mourning and Remembrance, Farnham: Ashgate Publishing Ltd.

Dehaene, M., and De Cauter, L. (eds), 2008, Heterotopia and the City: Public space in a postcivil society, London: Routledge.

Foucault, M., 1967, 'Of other spaces', in M. Dehaene and L. De Cauter (eds), 2008, Heterotopia and the City: Public space in a postcivil society, London: Routledge.

Friends of Tower Hamlets Cemetery Park, 2014, viewed 18 June 2014, www. fothcp.org/.

Johnson, P., 2008, 'The modern cemetery: A design for life', Social \& Cultural Geography, vol. 9, no. 7, pp. 777-90.

Larkins, R., 2007, Funeral Rights: What the Australian 'Death-Care' Industry Doesn't Want You to Know, Camberwell: Penguin.

Maddrell, A. and Sidaway, J. (eds), 2010, Deathscapes: Spaces for Death, Dying, Mourning and Remembrance, Farnham: Ashgate Publishing Ltd.

Martin, S., 2004, 'Monuments in the garden: The garden cemetery in Australia', Postcolonial Studies, vol. 7, no. 3, pp. 333-52.

Rugg, J., 2006, 'Lawn cemeteries: The emergence of a new landscape of death', Urban History, vol. 33, no. 2, pp. 213-33. 
craft + design enquiry

Sloterdijk, P., 2013, You Must Change Your Life, W. Hoban (trans.), Cambridge: Polity Press.

Worpole, K., 2003, Last Landscapes: The Architecture of the Cemetery in the West, London: Reaktion Books. 
This text is taken from Craft + Design Enquiry, Issue 7, 2015, edited by Kay Lawrence, published 2015 by ANU Press, The Australian National University, Canberra, Australia. 